\title{
Molinos hidráulicos harineros en Coquimbo (Chile, 1544-1750)
}

Pablo Lacoste y Alejandro Salas

PALABRAS CLAVE: molinos harineros hidráulicos, industrias tradicionales, economía colonial.

CÓDIGOS JEL: N16, N56, N96, 033.

e examina el proceso por el cual el corregimiento de Coquimbo sentó las ba$\circlearrowleft$ ses para convertirse en el principal polo molinero de Chile, cuando este reino era el mayor productor de trigo de América del Sur. Se estudia la evolución de los molinos hidráulicos en este corregimiento desde la fundación de La Serena (1549) hasta mediados del siglo XVIII a partir de documentos originales del Archivo Nacional. Se detecta la importancia del legado de los pueblos indígenas en la construcción de redes de canales de riego para la agricultura. Sobre esta base, los colonizadores españoles tuvieron ventajas para instalar la cultura molinera hidráulica europea. Se identifica el papel de artesanos especializados, tanto indígenas como afrodescendientes e hispanocriollos. Se detecta que los molinos operaron como polos de consolidación de mercados y referentes para la configuración de las rutas del comercio regional. 


\title{
Hydraulic Flour Mills in Coquimbo (Chile, 1544-1750)
}

\author{
KEYWORDS: hydraulic flour mills, traditional industries, colonial \\ economy.
}

JEL CODES: N16, N56, N96, 033.

Wis paper examines the process by which the Corregimiento de Coquimbo
become the main mill pole of Chile, when this kingdom was the largest
wheat producer in South America. The evolution of hydraulic mills in this township from the foundation of La Serena (1544) to the middle of the $18^{\text {th }}$ century is studied from original documents of the National Archive, especially Royal Audience and Notaries of La Serena. The importance of the legacy of indigenous peoples in the construction of irrigation canal networks for agriculture is detected. On this basis, the Spanish colonizers had advantages to install the European hydraulic mill culture. The role of specialized artisans, both indigenous and Afro-descendant and Spanish-Creole, is identified. It is detected that the mills operated as poles of consolidation of markets and benchmarks for the configuration of regional trade routes.

Recepción: 2020-05-12 - Revisión: 2020-11-09 • Aceptación: 2020-11-10

Pablo Lacoste [orcid.org/0000-0003-1876-8141] es catedrático del Instituto de Estudios Avanzados, en la Universidad de Santiago de Chile. Dirección para correspondencia: Froebel, 1705, Providencia (Chile). C. e.: pablo.lacoste@usach.cl

Alejandro Salas [orcid.org/0000-0001-7410-7968] es magister en Estudios Internacionales por la Universidad de Santiago y ayudante de investigación en la Universidad de Santiago de Chile. Dirección para correspondencia: Román Diaz, 89, Providencia (Chile).C.e.:alejandro.salas@usach.cl 


\section{INTRODUCCIÓN}

El molino tuvo un papel destacado en el proceso de producción de alimentos en América Latina entre los siglos XVI y XIX. Durante la colonización europea, los molinos se propagaron con rapidez por buena parte del Nuevo Mundo. En los ingenios azucareros de las Antillas se usaron molinos movidos a sangre (tahonas), traccionados por animales y esclavos (Romero, 2009), hasta que, hacia fines del siglo XVIII se comenzaron a introducir molinos hidráulicos (Naranjo, 2017: 220). En el Río de la Plata durante todo el periodo colonial el trigo se molía en tahonas tiradas por mulas y caballos (Eizkovicz, 2013), mientras que los molinos hidráulicos se aplicaron en México, Colombia, Perú, Chile y el oeste de Argentina (Cavieres, 1993; Cortés, 2003; Satizábal, 2004, 2018; Figueroa, 2006; Pereira, 2013. Premat, 2015, Lacoste, 2018). Por lo tanto, de Mesoamérica hasta el Cono Sur, las Indias dieron continuidad a la tradición molinera del Viejo Mundo (Díaz, 2010). Estas redes molineras permitían moler la harina y facilitaban el consumo del cereal que ocupaba un lugar central en la dieta española medieval y moderna (Barrio, 2009).

El abastecimiento triguero del Imperio español en América se organizó en torno a sus dos principales virreinatos, cada uno con sus propios proveedores. En Mesoamérica, el Virreinato de Nueva España se abastecía de la producción de México, mientras que en América del Sur, el Virreinato del Perú tuvo su principal polo triguero en Chile (Lacoste, 2018). De allí el interés por conocer los molinos harineros en estos núcleos. Paradójicamente, los dos polos molineros han sido abordados en forma asimétrica por la academia. Los historiadores han estudiado en profundidad los molinos de México y su impacto social, económico y cultural (Artís, 1986; López, 2002; Morales, 2006; Gómez Gerardo, 2007, 2016; Morales, 2008, 2010; Espinosa, 2012). En cambio, en Chile, los sistemas molineros han recibido atención menor, y solo focalizada en los siglos XVIII y XIX (Figueroa, 2006; Lacoste, 2018), de modo que queda pendiente el estudio del tema en los siglos XVI y XVII.

Uno de los polos molineros más dinámicos de Chile fue el Norte Chico, organizado administrativamente como corregimiento de Coquimbo con capital en La Serena, cien leguas al norte de Santiago. Las demandas peruana e interna estimularon la producción de trigo y los campos de Coquimbo se convirtieron en los mejor cultivados de Chile (Cortés, 2003). Los molinos se multiplicaron en la región hasta que, en 1813, se hizo visible su liderazgo. En efecto, el censo de ese año detectó que el arzobispado de Santiago contaba con 350 molinos para una población de 270.000 habitantes. Dentro de este espacio se destacaba el corregimiento de Coquimbo, que representaba el $11 \%$ de la población (29.000 habitantes) y el $16,5 \%$ de los molinos (53 establecimientos). El 
corregimiento de Coquimbo tenía una proporción de dos molinos cada mil habitantes, lo cual resulta notable para el contexto hispanoamericano de la época. ¿Cómo se explica este liderazgo regional en la industria molinera?

El presente estudio se propone indagar el proceso de introducción y expansión de los molinos hidráulicos harineros en el corregimiento de Coquimbo, desde la fundación de La Serena (1549) hasta mediados del siglo XVIII. Este territorio tenía una superficie de $33.000 \mathrm{~km}^{2}$ con una población de 6.400 habitantes en $1700,15.000$ en 1766 y 29.000 en 1813 (Cortés, 2018). La historia de Coquimbo ha sido tratada en forma parcial e incompleta debido a las dificultades para acceder a las fuentes. El ataque del pirata inglés Bart Sharp en 1680 causó la destrucción del edificio del cabildo y con él, se perdieron las actas capitulares y numerosos documentos (Concha, 1871). A ello se suma la dificultad para revelar fuentes del siglo XviI por su mayor complejidad paleográfica, lo cual requiere conocimientos muy especializados. Por este motivo, la historiografía colonial de La Serena se ha orientado principalmente al siglo XVIII (Concha, 1871; Amunátegui, 1928; Pinto, 1980; Cavieres, 1993; Lacoste, 2016, Cortés, 2018). En cambio, para el siglo XVII, la producción historiográfica es muy menor y se orienta principalmente a estudios sobre la estructuración de la propiedad (Cortés, 2003; Pizarro, 2014).

Para profundizar en el estudio de los molinos de Coquimbo, el presente estudio se apoya en los repositorios originales del Archivo Nacional de Santiago de Chile ${ }^{1}$. Sobre la base de esta masa de datos se ha constituido un corpus documental adecuado para conocer los dos primeros siglos de historia de la molinería regional, y conocer su influencia en el desarrollo económico, social y político del territorio.

\section{MOLINOS DE ESPAÑA A AMÉRICA COLONIAL}

En vísperas de la colonización de América, España había alcanzado un notable desarrollo de la molinería producto de la herencia árabe, que mejoró los ingenios romanos adaptándolos a sus necesidades. (Moreno \& López Gálvez, 2012). Desde el siglo X se construyeron molinos en los ingenios azucareros y, en las dos centurias siguientes, los molinos de viento alcanzaron un notable desarrollo y difusión en al-Ándalus. Por lo general, el molino de tracción a sangre se utilizaba para moler aceitunas, mientras que los molinos hi-

1. Se han compulsado los 19 volúmenes del Fondo Notariales de La Serena (FNLS) del Archivo Nacional Histórico de Chile (AN). De forma complementaria se ha examinado en el Fondo Real Audiencia (FRA) los volúmenes 587 (administración de la Hacienda Quilacán) y 666 (padrón de 1738). 
dráulicos se dedicaban preferentemente para moler granos de cereal y obtener harina (Moreno \& López Gálvez, 2012; Pedregosa \& Jiménez Comino, 2012).

Dentro del conjunto de los molinos harineros hidráulicos, la cultura española desarrolló dos líneas principales: aceña (rueda vertical) y rodezno (rueda horizontal). La aceña se utilizó junto a los grandes ríos y sus afluentes principales; en cambio los molinos de rodezno se aplicaron preferentemente en zonas alejadas de los grandes ríos, pues se alimentaban de cursos de agua secundarios, como acequias y canales de riego (Córdoba, 2002). Por lo general, se utilizaba la palabra molino para el de rodezno, mientras que el de rueda vertical se denominaba usualmente aceña (Córdoba, 2003).

Los molinos españoles tuvieron un papel destacado en el proceso de modelar los paisajes culturales. Los molinos se constituían en referentes para viajeros, comerciantes y transportistas, y emergían como cruces de caminos (Ortega, 2018). Los molinos tuvieron una función política, al influir en el trazado de rutas y caminos que, con el tiempo, influyeron en la demarcación de unidades administrativas y en la geografía política. A veces se agrupaban formando sistemas molineros específicos (Kirchner, 2011) que permitían asegurar el abastecimiento de los mercados locales y externos con sus propias dinámicas.

Los molinos tuvieron también efectos sociales, pues contribuyeron a fortalecer el estatus social de los grupos señoriales. Porque justamente estos actores eran los que disponían de los recursos para instalarlos, tanto la influencia política para obtener derechos de uso del agua como los capitales para financiar sus instalaciones y mantenimiento (Bloch, 1935: 552-553). En el caso de España, el molino gozaba de gran prestigio porque su capacidad de proveer del alimento diario lo dotaba de un alto significado económico, político y social. La nobleza y el sector eclesiástico se interesaban vivamente por poseer molinos debido a su significado como factor de prestigio (Pedregosa \& Jiménez Comino, 2012). El enorme valor del molino, con sus múltiples implicancias, estaba plenamente instalado en la conciencia española en vísperas de la colonización de América.

La expansión de los europeos en el Nuevo Mundo fue acompañada por sus culturas alimentarias, en las cuales un lugar central cupo a la dieta mediterránea, centrada en sus tres productos emblemáticos: trigo, vid y olivo. Los españoles trasladaron sistemáticamente a América los recursos necesarios para garantizar el acceso a esta dieta, lo cual incluía tanto plantas como equipamiento e instalaciones para su elaboración (lagares, tinajas, molinos). Dentro de este proceso general se encuentra la rápida expansión de los molinos hidráulicos harineros en el Nuevo Mundo. 
Allí donde los colonizadores europeos se establecieron, surgieron los molinos. En relativamente poco tiempo, la tecnología molinera se extendió del Atlántico al Pacífico, de Mesoamérica a América del Sur. Dentro de este último territorio se distinguieron dos grandes grupos: tahonas y molinos hidráulicos. En el Río de la Plata se usaron regularmente las tahonas, cuya capacidad de molienda rondaba entre tres y cuatro fanegas por día; al ingresar el primer molino a vapor (1846), funcionaban en Buenos Aires 62 tahonas (Eizykovicz, 2013: 182). En cambio, en Nueva Granada, Perú, Chile y el oeste argentino se desplegaron los molinos hidráulicos de rodezno.

Los dibujantes de la época representaron un molino hidráulico en el Perú. El más importante testimonio corresponde a la colección de estampas del obispo de Trujillo, Baltasar Martínez Compañón, en la cual se representa un molino en el norte del Perú en la segunda mitad del siglo XviII. Esta ilustración daba cuenta de las principales piezas del molino: rodezno, palahierro, piedras de moler y tolva. También se representaron los edificios que albergaban este equipamiento y el impactante curso de agua que servía de fuerza motriz ${ }^{2}$. Por lo general, el edificio del molino tenía dos plantas, la inferior para el rodezno y la superior para las piedras de moler y la tolva. Por lo tanto, el molino sobresalía de la línea general de edificación (formada habitualmente por viviendas de una sola planta) y emergía como referente del paisaje (Figueroa, 2006). Además, la complejidad de sus instalaciones en constante movimiento causaba un fuerte impacto de fascinación: el molino adquiría así un significativo papel como inteligencia desplegada, lo cual acentuaba el prestigio social de sus propietarios.

\section{BASES DE LA FUERZA MOTRIZ: CANALES DE RIEGO INDÍGENAS}

A primera vista, el territorio de Coquimbo parecía poco atractivo para la colonización española debido a su aridez. La escasez de lluvias en la costa y los valles determinaba que las actividades agropecuarias serían muy difíciles de realizar en este lugar. Las precipitaciones solo eran abundantes 200 kilómetros al este de La Serena, en la cordillera de los Andes, donde caía en forma de nieve que luego formaba los ríos Elqui, Limarí y otros. A partir de estos cursos de agua, los pueblos indígenas diseñaron y construyeron ingeniosos sistemas de riego que permitieron desarrollar la agricultura regional. En vísperas de la llegada de los españoles, la provincia de Coquimbo estaba habitada por las culturas diaguita e inca que, entre muchos grandes legados que dejaron, habían construido redes de canales de riego que sentaron las bases para el desarrollo y promoción de la agricultura

2. Las ilustraciones, junto con un glosario de vocablos específicos, pueden encontrarse en el anexo en línea: https://doi.org/10.26882/histagrar.085x031 
dentro de la región y mejoraron sustancialmente la alimentación de los pueblos allí localizados (Cerda, 2015). Este sistema sería utilizado luego por los colonos hispanos, por lo que constituyó un antecedente explicativo del auge molinero posterior (Cortés, 2003). ${ }^{3}$

Las obras hidráulicas legadas por incas y diaguitas se situaban dentro de un proceso mayor, signado por tres conceptos paralelos: la cultura del agua, la cultura del riego y la cultura agrícola. Los pueblos indígenas desarrollaron estas tres ideas en el territorio de Coquimbo. Y eso fue, justamente, lo que detectaron los cronistas y viajeros cuando tuvieron oportunidad de recorrer el Norte Chico, como Vivar (1558) y Ovalle (1646). Siglos después, los arqueólogos comprobaron el legado de cultura del riego, del agua y del agro en la región (García \& Damiani, 2020; Iniesta, Ots \& Manchado, 2020).

Los españoles aprovecharon esos sistemas de riego para cultivar sus propias plantas: «Por las acequias hay hierbas de nuestra España que son cerrajas, apio, hierba mora, llantén, verbena y de otras maneras de hierbas» (Vivar, 2001: 81). Pero el cultivo más importante fue el trigo, tal como escribió el primer gobernador de Chile (Valdivia, 1929: 41). La producción de trigo generó rápidamente la necesidad de molienda y allí estaban los canales indígenas para facilitar la instalación de los molinos hidráulicos.

\section{EL SISTEMA MOLINERO DE LA SERENA}

En el corregimiento de Coquimbo se conformaron tres sistemas molineros, en forma análoga a lo que ocurría en algunas regiones de España (Kirchner, 2011). Los sistemas molineros contaban con actores, estructuras y procesos que permitían insertarse en el tejido socioeconómico local. El primer sistema molinero regional surgió en torno a la ciudad de La Serena. El segundo se asentó a lo largo del valle de Elqui, junto al corredor trasandino que conectaba con el espacio rioplatense-pampeano; y el tercero se instaló en la cuenca del río Limarí, cien kilómetros al sur, en el cruce de caminos que conducía hacia el sur (para llegar a la ciudad de Santiago) y hacia el este y sudeste, para abastecer los yacimientos mineros de Tulahuen y Combarbalá (Fig. 1).

El sistema molinero de La Serena fue el primero de los tres y sirvió de modelo para todo el corregimiento. En efecto, el primer molino registrado se levantó en la capital regional en la segunda mitad del siglo XVI y fue levantado por don Hernando Aguirre (15281605), hijo del fundador de La Serena, Francisco de Aguirre. Junto con una fortuna ma-

3. El francés Frézier prestó particular atención a la acequia de la ciudad en su mapa de 1713 (Figura A3). Ver https://doi.org/10.26882/histagrar.085x031 
FIGURA 1

Sistemas Molineros del corregimiento de Coquimbo, siglos XVI-XVIII

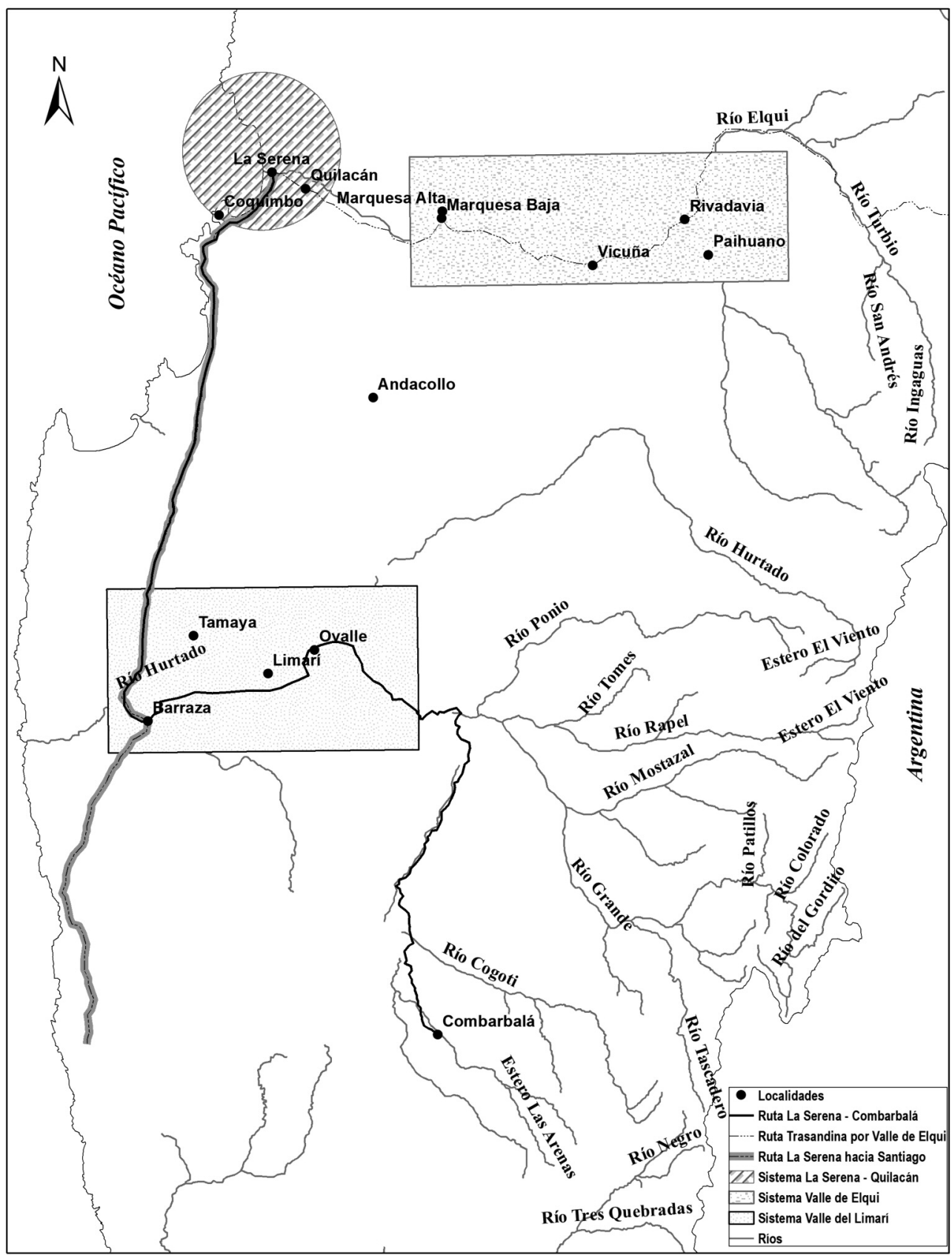

Fuente: elaboración propia a partir de documentos de FNLS y FRA (AN); cartografía de Bibiana Rendón. 
terial, don Hernando heredó de su padre una encumbrada posición social y política. Entre otros cargos importantes fue alcalde del Cabildo de La Serena y corregidor de Coquimbo. Referente principal de los grupos señoriales de la región, los usos y costumbres de la sociedad hispanocriolla establecían que don Hernando tenía que, naturalmente, asumir la misión de levantar el primer molino del corregimiento.

El molino de Aguirre contribuyó al prestigio del asentamiento español, al ofrecer a la población circundante la posibilidad de eludir el pesado esfuerzo de moler el grano a mano. Esta ventaja se trató de aprovechar como compensación, al menos parcial, de la pérdida y el dolor causado a los pueblos de la tierra a partir de la ocupación europea del espacio. Junto con afirmar la presencia española, el molino contribuyó a fortalecer el prestigio de las capas señoriales, y particularmente de la familia fundadora. Varios años después de la muerte de su fundador, esta construcción era conocida como «el molino de Hernando de Aguirre" y servía como referencia del paisaje, tanto para orientar a los viajeros como para deslindar propiedades y terrenos ${ }^{4}$. La presencia de esta construcción era tan notable que su nombre se trasladó también al canal de riego, que cambió su nombre y pasó a llamarse "acequia del molino», según se documentó en $1612^{5}$. Poco a poco, el molino afirmaba su posición dentro de los imaginarios sociales de la ciudad.

La tipología del establecimiento de Aguirre se ajustaba a las características generales de los molinos de rodezno localizados en las ciudades españolas. La fuerza motriz no provenía directamente del río, sino del canal de riego. La fuerza se transmitía del rodezno a las piedras de moler a través del palahierro; el grano se descargaba en las muelas a través de la tolva ${ }^{6}$. Este molino se convirtió en un referente regional y sirvió de modelo para el desarrollo posterior: los molinos construidos en Coquimbo en los tres siglos posteriores siguieron este mismo patrón.

El sistema molinero de La Serena siguió el patrón de la tradición española: los molinos fueron propiedad de los grupos señoriales y las órdenes religiosas. En los siglos XVI y XVII estos fueron los únicos grupos que disponían de los medios políticos para obtener los derechos de uso del agua de los canales, y los medios económicos para financiar la construcción y la operación de los molinos. En el marco de la matriz cultural española, los grupos señoriales de Coquimbo se interesaron por levantar molinos debido al prestigio social que estas instalaciones representaban (Pedregosa \& Jiménez Comino, 2012). Después de Aguirre, las familias privilegiadas que recibieron las principales mercedes de

4. AN, FNLS, vol. 2, fs. 567-572, "Carta de Dote y Arras», La Serena, febrero de 1616.

5. AN, FNLS, vol. 2, f. 425, "Carta de Dote», La Serena, 08/12/1614.

6. AN, FNLS, vol. 6, "Testamento de don Francisco de Riveros Figueroa», La Serena, 22/01/1620. 
tierras del territorio en la etapa de asentamiento español también se interesaron en levantar molinos en sus haciendas (Cortés, 2003).

La cercanía del sistema molinero de La Serena con la sede del Cabildo facilitó las condiciones para que buena parte de los propietarios de estas instalaciones fueran, a la vez, miembros de esta corporación municipal. Así se ha podido comprobar a partir del cruce de los nombres de propietarios con las listas de los miembros del Cabildo. Esta convergencia se vio facilitada por el carácter venal del sistema capitular: los cargos se vendían al mejor postor y, por lo general, solo los podían comprar receptores de mercedes de tierras y demás privilegios. Por lo tanto, la superposición de las autoridades con la lista de molineros de los siglos XVI y XVII era parte del proceso natural del nuevo orden establecido por los conquistadores. Por ejemplo, Jerónimo Pastene, igual que Hernando de Aguirre, fue corregidor de Coquimbo; Juan Antonio Callejas, Antonio Gómez Galleguillos y Pedro de Miranda fueron alcaldes del Cabildo de La Serena; el último fue también regidor, lo mismo que Germán Ramos de la Torre. La nota diferente la dio Juan de Valdovinos, que no ocupó cargos políticos por ser extranjero: era un acaudalado comerciante proveniente de los Países Bajos, enriquecido con el comercio de esclavos.

El uso de grados militares fue otro indicador relevante de la distinción social de los dueños de molinos del sistema molinero de La Serena. En esta región, el protagonismo de lo militar comenzó desde la fundación de la ciudad, dado el perfil de su fundador: basta recordar que el capitán Francisco de Aguirre era un tercio español de destacada carrera en Europa, que incluía las campañas de Italia y la toma de Roma en 1527 (Concha, 1871: 16-17). Don Francisco de Aguirre estaba rodeado por los símbolos del prestigio asociados al valor militar, cualidad muy apreciada en la sociedad formada por los conquistadores españoles del Reino de Chile.Y esta impronta se prolongó en el tiempo entre las familias prominentes del corregimiento de Coquimbo.

Los grados militares no eran jerarquías efectivas de carácter castrense, porque el corregimiento de Coquimbo carecía de ejércitos permanentes. Solo contaba con milicias que eventualmente se organizaban para hacer frente a posibles ataques de piratas británicos, como Francis Drake (1579) y Bart Sharp (1680). Paradójicamente, esas acciones eran ocasionales, pero los grados militares eran permanentes como distinción social.Y los dueños de molinos se distinguían, precisamente, por ostentarlos: Juan Antonio Callejas tenía el grado de alférez; Pedro de Miranda y Jerónimo Pastene ostentaban el título de capitán; Antonio Galleguillos llegó más alto y alcanzó el grado de maestre de campo. Ellos no desempeñaban funciones castrenses, pero usaban los grados como símbolo de prestigio para establecer su lugar en la jerarquía social. 
Por su parte, las órdenes religiosas también asumieron un papel protagónico en este proceso, sobre todo los jesuitas: el mismo año que la Compañía de Jesús se instaló en La Serena, solicitó y obtuvo del Cabildo la autorización para utilizar el agua de la acequia pública como fuerza motriz de su molino (Concha, 1871: 20; Amunátegui, 1928). La orden valoraba la ventaja que el molino aportaba a la gestión cotidiana de la comunidad de religiosos: al no tener que distraerse en el penoso trabajo de la molienda de grano, sus miembros tenían más tiempo para dedicarse a sus actividades piadosas (Bloch, 1935). En el caso de los jesuitas, junto con sus objetivos piadosos, esta orden religiosa aprovechaba los beneficios del molino para sus redes productivas regionales.

El sistema molinero capitalino se destacaba por la diversificación de su mercado y su estabilidad. En efecto, los molinos de este sistema debían abastecer tanto las minas de oro de Andacollo como el abasto de la ciudad de La Serena y la demanda del puerto de Coquimbo, donde los barcos mercantes requerían regularmente bizcochos y galleta como rancho para la tripulación. Estos tres polos significaron una demanda constante de harina para los molinos del sistema molinero metropolitano, lo cual brindó un contexto adecuado para sostener los molinos en funcionamiento.

El flujo regular de harina contrastaba con la irregular producción y comercialización del trigo. La economía triguera estuvo sujeta a grandes oscilaciones debido a los ciclos de sequía causados por la corriente de El Niño. En los años buenos, las haciendas producían grandes cantidades de trigo, lo cual generaba excedentes para exportar a Copiapó y al Perú (Cortés, 2003). El mercado interno quedaba bien abastecido a bajos precios, con valores que oscilaban entre $\$ 2$ y $\$ 21 / 2$ por fanega de harina. Los panaderos la compraban y luego vendían el pan en el mercado, a precios cercanos a un real por 16 onzas de pan (1 libra) (Ramón \& Larraín, 1981: 120). La situación cambiaba radicalmente en los ciclos de escasez, muchas veces debido a la sequía causada por la corriente de El Niño. La producción de trigo caía verticalmente y se creaban tensiones entre las demandas locales y los requerimientos de los mercados externos. En estas circunstancias, el Cabildo asumía el papel de regulador de los mercados con medidas precisas. A través de las ordenanzas municipales correspondientes, el Cabildo restringía las exportaciones y, en algunos casos, llegó a prohibirlas. También estableció regulaciones de precio y prorrateos para asegurar el abastecimiento del mercado interno. En la década de 1690 los precios subieron hasta duplicar los niveles habituales: llegaron a $\$ 5$ por fanega de harina (Ramón \& Larraín, 1981). La escasez presionaba los precios al alza, creando tensiones sociales y crisis de desabastecimiento. El Cabildo de La Serena tomó entonces medidas para resolver el problema mediante nuevas regulaciones: en 1697 ordenó que los agricultores debían vender el $10 \%$ de la producción (400 fanegas) al mismo Cabildo, al precio de $\$ 3$ por fanega de harina. El regidor debía recibir la harina para finalmente vender la harina a los 
FIGURA 2

Rutas marítimas de Chile, siglos XVI-XIX

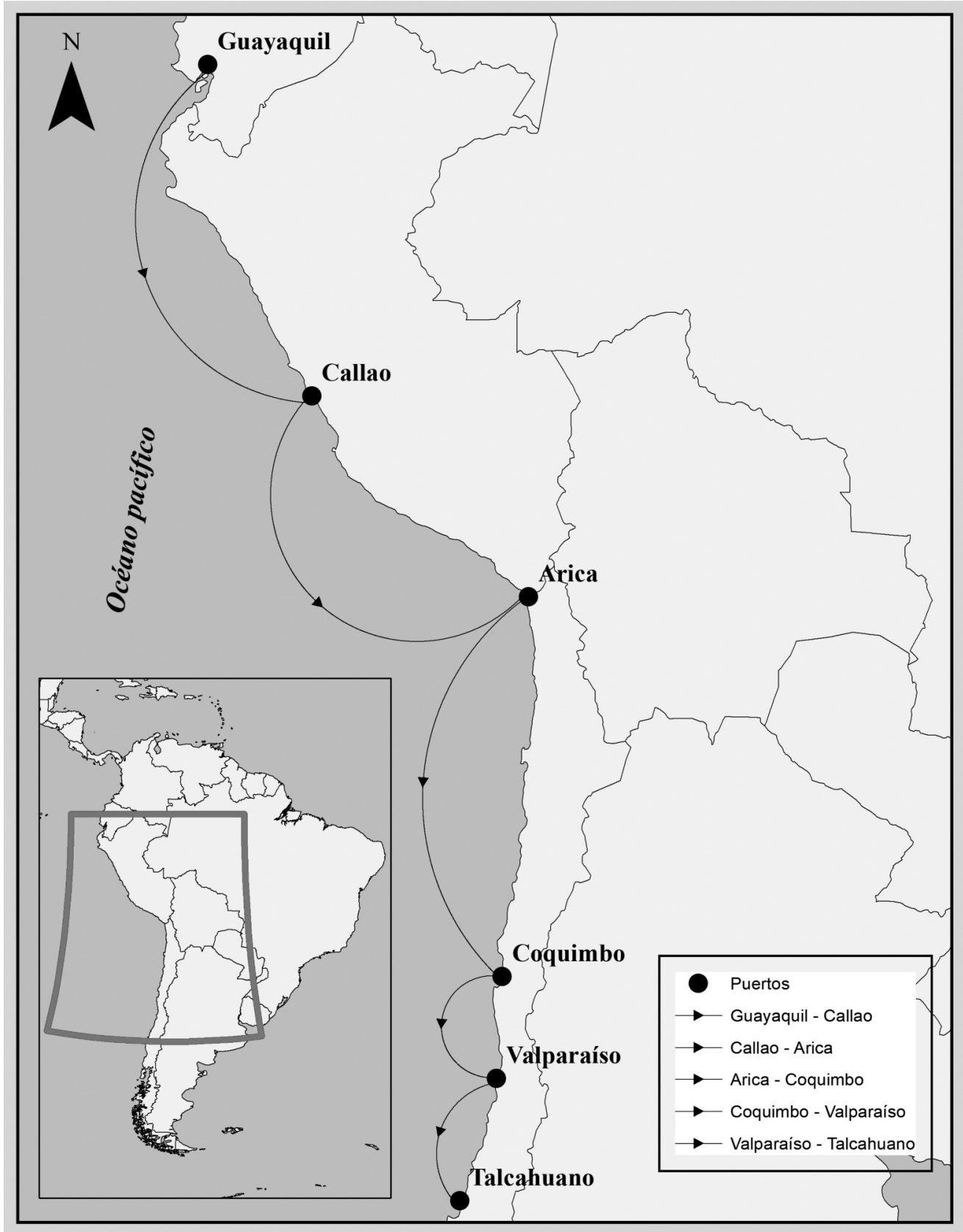

Fuente: elaboración propia; cartografía de Bibiana Rendón. 
panaderos a $\$ 4$ la fanega. La diferencia del precio de compra $(\$ 3)$ y el de venta ( $\$ 4)$ debía servirle para cubrir los costos de molienda y transporte (arrieros). A su vez, el Cabildo reguló el precio de venta de forma indirecta: el pan se seguía vendiendo a 1 real la unidad, pero esta bajó de 16 a 8 onzas (Amunátegui, 1928: 55). El pan elaborado bajo estas regulaciones estaba destinado exclusivamente a la población local y al servicio de rancho para los barcos mercantes que recalaban en el puerto de Coquimbo. Estas medidas regulatorias fueron aplicadas también en otras ciudades del Reino de Chile en los periodos de escasez de trigo y harina (Ramón \& Larraín, 1981: 120).

Con estos procedimientos, el Cabildo aseguraba el funcionamiento ininterrumpido del sistema molinero regional. Se alcanzaban los principales objetivos políticos y comerciales, al garantizar un abastecimiento mínimo para la población local y los barcos surtos en Coquimbo, a la vez que se lograba mantener los molinos en funcionamiento. La variable de ajuste eran los mercados externos y los intereses de los comerciantes dedicados a la exportación, que eran sistemáticamente postergados en ciclos de baja producción triguera. En estas decisiones, los capitulares exhibían la sensibilidad por el público, por las redes del comercio marítimo y por sus propios molinos.

El sistema molinero de La Serena contribuyó a consolidar esta ciudad como un polo capaz de asegurar el alimento diario, tanto para la población local como para los barcos que servían las rutas del Pacífico sur americano. Para los buques que realizaban viajes de 4.000 kilómetros de longitud, entre Guayaquil, El Callao, Valparaíso y Talcahuano, era importante disponer de puertos intermedios para abastecerse. Coquimbo tenía una localización privilegiada, porque era el último puerto antes de llegar a Valparaíso. Al disponer de la harina provista por los molinos locales, juntamente con el agua dulce del valle de Elqui, los vinos, piscos y demás alimentos, Coquimbo ofrecía una garantía de abastecimiento para los barcos de todo tipo que llegaban a la región. De este modo, el sistema molinero de La Serena contribuyó a la consolidación del puerto de Coquimbo dentro de las rutas comerciales marítimas de la época (Fig. 2).

La consolidación del puerto de Coquimbo facilitó la integración del corregimiento dentro del sistema económico regional del Imperio español. Estimuló la producción local de productos que luego se remitían al mercado peruano, sobre todo trigo, cobre y derivados de la ganadería: sebo, jabón, cueros y talabartería. Asimismo, facilitó el abastecimiento de los insumos que el corregimiento necesitaba para hacer funcionar su economía (sobre todo herramientas) y las necesidades de su población (indumentaria, azúcar y bienes suntuarios). La actividad portuaria afirmó la funcionalidad del corregimiento de Coquimbo dentro del sistema colonial español, a la vez que, en cierta forma, promovió la economía local, tanto de materias primas como de manufacturas. 


\section{SISTEMAS MOLINEROS VALLETANOS DE ELQUI Y LIMARÍ}

La consolidación de la actividad económica, social y política facilitó la expansión del proceso colonizador hacia el interior del territorio, hacia los valles de Elqui y Limarí, donde surgieron sendos sistemas molineros. A diferencia del sistema capitalino, orientado a fortalecer las rutas marítimas y la población urbana, los sistemas valletanos tuvieron un papel relevante en la consolidación de las rutas terrestres, la población rural y los yacimientos mineros.

El valle de Elqui tenía una extensión de cien kilómetros y se extendía desde La Serena hacia el este, para llegar a Rivadavia y Paihuano. Permitía vincular el puerto y la capital con los fértiles valles intermontanos y los mercados trasandinos. Los arrieros recorrían regularmente este camino para cruzar los Andes y llegar a Jáchal, cruce de caminos que permitían alcanzar después las provincias de Cuyo, Córdoba y Tucumán (Lacoste et al, 2016). El servicio regular de los arrieros permitía abastecer también los emprendimientos agrícolas, ganaderos y mineros de la región.

El sistema molinero del valle de Elqui presentaba similitudes y diferencias con su par capitalino. Los puntos de convergencia se situaban en el carácter señorial: las familias privilegiadas, beneficiadas por las mercedes de tierras, fueron las propietarias de los molinos emplazados en el valle de Elqui. Basta señalar que los primeros molinos surgieron en el seno de las familias más prominentes de la región: los Cortés Monroy eran dueños del molino de la hacienda de Rivadavia (90 kilómetros al este de La Serena), y los descendientes del gobernador Francisco de Aguirre eran los dueños de las haciendas de Marquesa la Alta y Marquesa la Baja (cerca de la actual villa de Vicuna) ${ }^{7}$. Se consolidaba así el carácter señorial de los molinos regionales.

La distancia del valle de Elqui a la ciudad de La Serena contribuyó a marcar diferencias con el sistema molinero capitalino, porque los caminos eran muy precarios y, por lo general, solo los arrieros se animaban a recorrerlos de modo habitual. Los hacendados evitaban viajar regularmente a La Serena porque el viaje era largo, incómodo y molesto. Por este motivo, tenían poco interés en asumir compromisos en el Cabildo. Esta corporación no ocupaba un papel relevante en su horizonte.

7. AN, FNLS, vol. 2, f. 202, "Carta de Emancipación de don Francisco Cortés», La Serena, 27/08/1613. 
La distancia a La Serena significaba ventajas y desventajas. Los hacendados del valle de Elqui tenían menor influencia política, pero, a la vez, gozaban de más autonomía y debían someterse a menos regulaciones en el manejo de sus producciones. El sistema molinero valletano quedó exento de las regulaciones y precios máximos que cíclicamente se imponían a la producción capitalina. Algo parecido ocurría con relación al puerto de Coquimbo: los molinos elquinos no debían asumir responsabilidades para su abasto.

La misión estratégica de los molinos de Rivadavia y Marquesa la Baja fue asegurar las provisiones para la producción minera local, la ganadería, la agricultura y la elaboración de vinos, aguardientes y piscos (Lacoste, 2016; Cofré \& Stewart, 2020). También prestó servicios de abastecimiento a los arrieros que subían y bajaban la cordillera de los Andes, transportando yerba mate, jabón de Mendoza y ganado en pie desde las pampas rioplatenses hacia el corregimiento de Coquimbo, y alambiques de cobre labrado y otros bienes en el sentido contrario (Lacoste, Lacoste \& Mujica, 2019). La seguridad de contar con un centro de abastecimiento a lo largo de buena parte del viaje representaba una mejora sustancial de las condiciones de transitabilidad para las rutas de larga distancia.

El rancho de viaje del arriero estaba formado por diversos alimentos, como charqui (carne deshidratada), ají, cebolla, ajo, queso de cabra y, fundamentalmente, harina tostada, principal aporte de hidratos de carbono para sostener los viajes a través de la cordillera nevada, con sus altas cumbres y sus bajas temperaturas. La presencia del molino tenía un gran valor para los arrieros, tanto en sus viajes de ida como de regreso, porque ofrecía la seguridad de contar con los alimentos fundamentales. El aporte de los molinos del valle de Elqui se complementaba con los asentamientos homólogos en la vertiente oriental de los Andes. Allí surgieron también molinos harineros que daban continuidad a la cadena de abastecimientos. Entre otros establecimientos, a comienzos del siglo XVII surgió el molino San Francisco, situado en la localidad de Chilecito, en la ruta que conducía desde Jáchal hacia el norte ${ }^{8}$.

La consolidación del corredor trasandino por el valle de Elqui, facilitada por las redes de molinos harineros, permitió el fortalecimiento del arriero como señor de la cordillera. Su aporte trascendió la promoción de la actividad económica y comercial, y le permitió también funcionar como intermediador etnobotánico. En sus recurrentes viajes, el arriero contribuyó con la propagación de distintas especies de plantas, entre ellas la moscatel de Alejandría, variedad de vid que ingresó a Chile a comienzos del siglo XvIII a tra-

8. El molino San Francisco de Chilecito se conserva en la actualidad como museo. La toponimia de la ciudad, Chilecito, es un testimonio del viaje regular de arrieros chilenos a través de la cordillera de los Andes. 
vés de la ruta del valle de Elqui, lo cual contribuyó al proceso de diversificación del patrimonio vitivinícola chileno (Lacoste et al., 2020) ${ }^{9}$.

Los sistemas molineros del corregimiento de Coquimbo se completaron con el surgimiento del tercer conjunto en el valle de Limarí. Este tuvo elementos en común con los dos sistemas anteriores, a la vez que tuvo sus propias características. Los aspectos comunes se hallaban en su carácter señorial, fundamentalmente, mientras que las diferencias se encontraban en las rutas y actividades económicas que servían. Lejos de la ciudad de La Serena y del puerto de Coquimbo, el sistema molinero de Limarí tuvo menos vínculos con las actividades capitalinas; pero tuvo papeles destacados en el transporte de larga distancia para vincular el corregimiento con la capital del reino y sobre todo, para facilitar el transporte y las comunicaciones con las faenas mineras de Combarbalá, Tulahén y otras.

Igual que en los casos anteriores, el sistema molinero de Limarí surgió asociado a los grupos señoriales. El proceso comenzó con la ocupación del espacio por parte de los colonos españoles en los siglos XVI y XVII cuando se distribuyeron amplios territorios mediante mercedes de tierras para retribuir servicios prestados a la Corona. Cientos de miles de hectáreas se distribuyeron entre las familias privilegiadas para poner en marcha emprendimientos mineros, ganaderos y agrícolas (Cortés, 2003). El núcleo del sistema se estableció en torno a la localidad de Barraza, sobre la ribera izquierda del río Limarí, veinte leguas al sur de La Serena. Allí surgió la hacienda Barraza y en sus inmediaciones, los Pizarro levantaron su propio molino, el cual se convirtió en polo de referencia para la localidad. Una de las hijas de Francisco de Aguirre recibió como dote la hacienda Rucapini, en la cual se levantó un molino hidráulico administrado por su marido, Pedro Pastene. Esta familia amplió la actividad con la instalación de un molino en la hacienda Limarí, propiedad de Jerónimo Pastene. Por su parte, don Juan Domínguez Marín y Cadimos tomó posesión de la hacienda Talmecura en la década de 1610, en la cual también se instaló un molino, dedicado a abastecer a los pirquineros que explotaban el mineral de Tamaya, situado a 15 kilómetros de Barraza (Arre, 2017). Poco a poco se consolidó el sistema molinero de Limarí con cuatro activos molinos ${ }^{10}$.

9. La Figura A4 representa las rutas terrestres del corregimiento de Coquimbo. Ver anexo en línea https://doi.org/10.26882/histagrar.085x031

10. AN, FNLS, vol. 4, fs. 12v-16, "Testamento de don Diego Pizarro del Pozo y Clavijo», Limarí, 28/01/1643; AN, FNLS, vol. 4, f. 33, «Inventario de bienes de don Diego Pizarro», valle de Limarí, 13/09/1655; AN, FNLS, vol. 16, f. 87, "Testamento de Rodrigo de Rojas y Riveros», La Serena, 13/11/1693; AN, FNLS, vol. 15, f. 228, "Imposición de capellanía en favor del convento franciscano", La Serena, 05/06/1700; AN, FNLS, vol. 8, f, 187, «Inventario de bienes de la Hacienda Rucapini», valle de Limarí, junio de 1710. 
El perfil señorial de los establecimientos molineros también se consolidó en este territorio. Además de tener estrechos vínculos con las familias de la élite, los dueños de los molinos también ostentaban cargos políticos relevantes: Marín y Cadimos fue alcalde de La Serena y corregidor de Copiapó y Huasco; Rojas y Riveros fue alcalde, regidor y procurador del Cabildo de La Serena. En cierto modo se reiteraba el patrón general del carácter señorial de los señores del molino. Dentro de este proceso hubo espacio también para la presencia del sector eclesiástico. Las órdenes religiosas también tomaron parte de este proceso, a través de los jesuitas. Estos adquirieron el molino de la familia Pastene (Cortés, 2003).

En comparación con el sistema molinero capitalino, el de Limarí tuvo menores vínculos con el mercado urbano serenense y el puerto de Coquimbo debido a la distancia. Su objetivo principal era abastecer la demanda de las faenas mineras de Tamaya, Combarbalá, Punitaqui, Tulahuén, Quiles, Cerro Colorado, Llampagne y Llaguin (Cortés, 2003). Paralelamente, el sistema molinero de Limarí contribuyó al desarrollo de las rutas terrestres regionales. Barraza funcionó como cruce de caminos y allí se abastecían de harina tostada, tanto los arrieros que viajaban hacia los yacimientos mineros de la región como los que servían la ruta del sur para llegar a la capital, Santiago de Chile. De este modo, los tres sistemas molineros se complementaban para cumplir sus funciones estratégicas de asegurar las conexiones de transporte y comunicaciones del corregimiento de Coquimbo dentro de su propio territorio y con los mercados exteriores. Así, se lubricaron las rutas que facilitaban las actividades agrícolas, mineras, ganaderas y comerciales de estas provincias del Imperio español.

\section{EL MOLINO DE QUILACÁN Y SU MANO DE OBRA}

El molino mejor documentado del corregimiento de Coquimbo se encontraba en la chacra de Quilacán. Con motivo de un juicio entre el dueño y el administrador, se levantaron registros detallados de la propiedad a mediados del siglo XVII, lo cual ha facilitado el acceso a detallados inventarios del molino. Estaba localizado dos leguas al este de la ciudad de La Serena, en las puertas del camino que conducía al valle de Elqui y al corregimiento de Cuyo. Esta posición estratégica le facilitó insertarse en la vida socioeconómica de la época, como terminal de cargas para los arrieros.

La chacra de Quilacán estaba íntimamente asociada a una de las familias más prominentes del corregimiento de Coquimbo, los Cortés y Monroy, que luego obtuvieron el marquesado de Piedra Blanca. Este título de nobleza sirvió para consolidar el prestigio social de una familia de destacada trayectoria en la región, y realzar su liderazgo te- 
rritorial. En efecto, el molino de Quilacán surgió durante la administración de don Pedro Cortés Monroy y Cisterna (1613 y 1624) y se mantuvo en funcionamiento en las décadas posteriores. A mediados de la década de 1640 se realizó una renovación parcial del equipamiento que incluía las piedras, el canal de provisión de agua para mover el rodezno y el sistema de tolvas para alimentación de granos de trigo, juntamente con las medidas de seguridad para el edificio. La inversión en el mejoramiento del molino superó los $\$ 56$, tal como detalla la Tabla I.

\section{TABLA 1}

Mejoras al molino de chacra Quilacán, 1645-1648

\begin{tabular}{llr}
\hline Rubro & Concepto & Valor (pesos de 8 reales) \\
\hline Materiales & 1 tabla de alerce & $\$ 32$ reales \\
& 2 tablones grandes nuevos & $\$ 5$ \\
& 1 candado & $\$ 4$ \\
& 3 tablas de alerce & $\$ 4$ reales \\
& 1 sauce grueso y largo para marco y cajón de la piedra y para viga de la tolva & $\$ 2$ \\
& 100 clavos para canaleta & $\$ 3$ \\
& 2 picos que calzó para el molino y 6 clavos grandes para clavar dichas puntas en la reja & $\$ 2$ \\
& Subtotal & $\$ 236$ reales \\
\hline Fletes & Transportar tablas a Quilacán (arriendo de 4 bueyes) & $\$ 20$ \\
& Piedras de Andacollo a Quilacán (60 km) & $\$ 6$ \\
Subtotal & $\$ 26$ \\
\hline Total & Picar, asentar y ajustar piedras (indio Llagan) & $\$ 34$ reales \\
& Calzar dos picos para el molino (Ambrosio Herrero) & $\$ 2$ reales \\
& Poner acero para calzar los dichos picos & $\$ 1$
\end{tabular}

Fuente: elaboración propia a partir de AN, FRA, vol. 587.

El molino significaba un fuerte estímulo para el desarrollo de las artes y oficios. Su construcción y mantenimiento requería el servicio de carpinteros, herreros, terneros, ebanistas, escultores, albañiles y molineros, entre otros oficiales (Ramírez, 1984; Sahady, Bravo \& Quilodrán, 2016). Esta tendencia general de los molinos hispanoamericanos se hizo visible también en el corregimiento de Coquimbo. Allí había una diversidad de artesanos y mano de obra especializada. En Coquimbo había canteros, carpinteros, herreros y otros oficios. Los canteros tallaban piedras para los molinos; los herreros manufacturaban clavos, picos, cinchos para el rodezno y demás herramientas de trabajo; los carpinteros seleccionaban y elaboraban las maderas necesarias para el palehierro, el rodezno, la tolva y demás partes del molino. Estos servicios los proveían artesanos mestizos y afroamericanos, juntamente con los indígenas. 
En efecto, en la chacra de Quilacán se destacó un indígena que dominaba las técnicas de carpintería, cantería y montaje de molinos. En los documentos se lo llamaba «el indio Llagan", y era quien realizaba las tareas más delicadas y finas. A partir de madera de sauce, Llagan se encargó de manufacturar «el marco y cajón de la piedra del molino y una viga en que está puesta la tolva del dicho molino", por lo cual recibió $\$ 3$. Además, se le pagaron $« \$ 3 \frac{1}{2}$ en plata por el trabajo y ocupación que puso en picar y asentar y ajustar las piedras del dicho molino cuando se pusieron para empezar a moler». Su tarea consistió en marcar las estrías en la piedra del molino, de modo tal de facilitar el desplazamiento de la harina una vez molidos los granos de trigo, además del montaje y ajuste necesario para asegurar su funcionamiento. Evidentemente, el indio Llagan aprendió rápidamente las técnicas introducidas por los españoles y desplegó sus capacidades en los molinos regionales.

La abundancia de recursos en la próspera chacra de Quilacán y la asistencia técnica de Llagan permitieron al administrador mejorar sensiblemente el equipamiento y las instalaciones molineras. Al final de la administración, el 15 de abril de 1649, el encargado entregó la propiedad a su sucesora en el cargo, Francisca de Cartagena. En el inventario de los bienes se incluyó «un molino moliente y corriente con su casa y puerta y llave de candado de lobo con dos picadores con cuatro cinchos de hierro el rodezno» juntamente con «una piedra de molino que está fuera» ${ }^{11}$. Es decir, se había completado la renovación del molino con éxito y funcionaba regularmente. Además, se dejaba un juego de piedras de repuesto para cambiar en caso de rotura o desgaste de las piedras en funciones.

El constante servicio del molino de Quilacán permitió aprovechar su localización estratégica para constituir un terminal de carga para los arrieros que llegaban o salían hacia la ruta del valle de Elqui, juntamente con un espacio de sociabilidad y encuentro con los campesinos locales y los comerciantes y pulperos de La Serena. Los campesinos que llevaban los zurrones de trigo al molino para obtener la harina debían permanecer un tiempo en el lugar a la espera del producto. En ese lapso tenían la oportunidad de alternar con los arrieros, troperos (conductores de tropas de mulas), jornaleros y demás sujetos que circulaban por el lugar. La afluencia de público llevó a los administradores de la chacra a abrir allí una pulpería, lo cual generó mayor sinergia con el molino. Los transportistas de corta distancia, de las haciendas cercanas, y que solo llegaban al lugar para obtener la harina, se encontraban allí con los arrieros que se abastecían para llevar alimentos a Andacollo y otras faenas mineras. También intercambiaban conversaciones y productos con los arrieros de larga distancia, que iban o venían al corregimiento de Cuyo, y

11. AN, FRA, vol. 587, f. 57v, «Declaración del Administrador de la chacra de Quilacán», La Serena, 05/06/1649. 
los que circulaban hacia La Serena y el puerto de Coquimbo. El molino de Quilacán funcionaba como un polo convocante para aquellos arrieros, y reforzaba el sitio como espacio de encuentro o terminal de las tropas de cargas para el comercio regional. La conjunción del molino y la pulpería afirmó a Quilacán como un centro de consolidación del espacio económico y sociocultural.

Junto con su relevancia económica, el molino de Quilacán se convirtió también en símbolo de prestigio social. Tal como ocurría en España, los sectores de mayor estatus se interesaron por estas instalaciones molineras. A mediados del siglo XVII, el molino fue arrendado por un importante comerciante español asentado en Lima, don Celedón de Camus y posteriormente pasó a formar parte del marquesado de Piedra Blanca, una de las pocas casas nobles del Reino de Chile. En cierto modo, el molino se convirtió en plataforma del prestigio social de la familia propietaria, función que a partir del siglo XIX ocuparían los establecimientos vitivinícolas en Chile.

\section{LOS MOLINOS DE COQUIMBO EN 1738}

En la década de 1740 la población del corregimiento de Coquimbo llegó a los 7.000 habitantes. Ello significaba un incremento de apenas un $10 \%$ en cuatro décadas. Debido a su aridez, el Norte Chico no estaba entre los polos más dinámicos de la economía chilena. Sin embargo, dentro de su relativa estabilidad, este territorio ganaba en densidad y desarrollo interno, tal como se reflejó en la consolidación de las redes de molinos hidráulicos. La actitud de los hacendados, en el sentido de reinvertir utilidades para introducir mejoras, contribuyó a que sus propiedades ganaran en densidad y valor económico, lo cual facilitó el acceso al crédito y la posibilidad de nuevas inversiones. Las haciendas se consolidaron como espacios de producción diversificada, que incluían agricultura, ganadería y manufacturas. Además del cultivo del trigo y legumbres en tierras de pan llevar, se cultivaban viñas y huertos frutales. Para elaborar sus productos, se incorporaron instalaciones y equipamientos, como bodegas con sus lagares y tinajas, pailas y alambiques de destilación, molinos hidráulicos y talleres de carpintería y herrería. Asimismo, adoptaron los implementos necesarios para trabajar los cueros y fabricar cordobanes, odres, petacas, zurrones y demás piezas de talabartería, juntamente con las instalaciones para producir sebo y jabón. A ello se sumaban las fraguas para manufacturar cobres labrados, particularmente alambiques. En las áridas tierras del corregimiento de Coquimbo, las haciendas emergieron como dinámicos polos de producción diversificada (Cortés, 2003). Los detalles de este proceso se conocieron debido a hechos imprevistos. El incendio del Palacio Real de Madrid (1734) llevó a la Corona española a impulsar un impuesto universal para financiar la reconstrucción. Por este motivo, se realizó un deta- 
llado padrón de propiedades en las distintas colonias españolas, lo cual se convirtió en un registro de singular valor para los objetivos del presente estudio.

El padrón de 1738 detectó la presencia de nueve molinos harineros laicos: debido a los privilegios de la nobleza y el sector eclesiástico, no se registraron los molinos de las órdenes religiosas que eran por lo menos dos; ni los de la nobleza, que eran como mínimo cuatro (Quilacán, Marquesa la Alta, Marquesa la Baja y Rivadavia). Además, este censo solo registró dos molinos del sistema del valle de Limarí, donde existían al menos cuatro. Es posible que la ausencia de estos registros se explique por la tendencia a subdeclarar bienes para eludir impuestos. En todo caso, la cifra real de molinos era por lo menos el doble de la registrada. A pesar de sus limitaciones, el padrón entregó información relevante para comprender algunos aspectos de los sistemas molineros regionales.

El padrón de 1738 daba cuenta del conjunto de las propiedades, incluyendo equipamiento e instalaciones productivas (molinos, bodegas, lagares, tinajas), esclavos y ganado, tanto mayor (bovinos y equinos) como menor (ovinos y caprinos). Sobre la base de esta información se ha elaborado la Tabla 2, en la cual también se han añadido datos complementarios no consignados con el censo, como los cargos políticos ocupados por los propietarios de molinos en el Cabildo de La Serena.

TABLA 2

Propietarios de molinos registrados en el padrón de 1738

\begin{tabular}{|c|c|c|c|c|c|c|c|c|}
\hline \multirow[t]{2}{*}{ Dueño } & \multirow[t]{2}{*}{ Cargos políticos } & \multirow[t]{2}{*}{ Lugar } & \multicolumn{2}{|c|}{ Molinos } & \multirow[t]{2}{*}{ Esclavos } & \multirow{2}{*}{$\begin{array}{c}\text { Bodega } \\
\text { vino }\end{array}$} & \multicolumn{2}{|c|}{ Ganado } \\
\hline & & & Pan & Minero & & & Menor & Mayor \\
\hline Agustín Callejas & Alcalde, Procurador, Regidor & Valle de Elqui & 1 & 1 & 4 & $100 @$ & & 54 \\
\hline Cristóbal Callejas & Regidor, Alcalde & La Serena & 1 & - & 6 & $400 @$ & 700 & \\
\hline Agustín Sepeda & - & La Serena & 1 & - & 3 & $300 @$ & 300 & 100 \\
\hline Vicente Cortés & Alcalde & Monterrey & 1 & - & - & & & 30 \\
\hline Pedro Pizarro & Alcalde & Valle de Limarí & 2 & 1 & 2 & $200 @$ & 500 & 28 \\
\hline Juan de Vega & Alcalde, Procurador & Valle de Limarí & 1 & - & 2 & Viña & 200 & 120 \\
\hline Juan Fernando Moyano & - & Combarbalá & 1 & 1 & - & - & 80 & 35 \\
\hline
\end{tabular}

Fuente: elaboración propia a partir del padrón de 1738 (ANH, FRA, vol. 666, fs. 1-83) y de las listas de cargos en el Cabildo de La Serena (Amunátegui, 1928).

La Tabla muestra cierta continuidad en el perfil de los actores de los sistemas molineros del siglo XVIII con el siglo XVII. Los propietarios de molinos mantenían su secular presencia en los espacios de poder político, tanto en el corregimiento como en el Cabildo de La Serena. Muchos rotaban en posiciones de alcalde, procurador o regidor. El único dueño de molino que no formó parte del Cabildo fue Juan Fernando Moyano, cuya hacienda se encontraba muy alejada, en la casi inaccesible localidad de Combarbalá. 
El registro de los esclavos aporta otro dato significativo. Las siete haciendas con molino poseían en total 17 esclavos, lo cual implica una media de 2,4 esclavos por unidad productiva. Esta situación distaba considerablemente del modelo de las haciendas de plantaciones tropicales (azúcar, café, algodón, cacao, tabaco), situadas en el Caribe, el sur de América del Norte y el norte de América del Sur, signadas por decenas o cientos de esclavos. En el caso de Chile, como en otras regiones de clima templado, no se verificaron esas modalidades de economía de plantación. De todos modos, a pesar de su acotado número, la presencia de esclavos marcaba la persistencia de las prácticas del Antiguo Régimen y del sistema caracterizado por tener las jerarquías sociales fuertemente marcadas. Por lo general estos esclavos se destacaban por el dominio técnico de artes y oficios: eran carpinteros, herreros y talabarteros, lo cual les permitía contribuir al mantenimiento de las instalaciones molineras.

Junto con asegurar el funcionamiento de los molinos, la presencia de los esclavos en estas haciendas representaba la dimensión humanamente más dramática del sistema. Los esclavos estaban sometidos a condiciones de alta vulnerabilidad emocional, sobre todo cuando sus propietarios resolvían vender o rematar a los niños (Cortés, 2018). Este mecanismo dejaba a las familias esclavas ante el constante riesgo de perder a sus hijos para siempre cuando estos eran comprados para el mercado peruano. A ello se sumaba el rigor de la vida laboral. Para disciplinar a sus esclavos, las haciendas contaban con instrumentos específicos, como calabozos, cepos, grillos. En determinadas ocasiones, los esclavos eran castigados por los dueños o administradores de las haciendas, lo cual generaba situaciones de dolor, frustración e injusticia. Las tensiones generadas por este sistema contribuyeron a crear las condiciones para promover las ideas revolucionarias y las guerras de emancipación a comienzos del siglo XIX.

Los datos del padrón entregan información relevante sobre la pluriactividad de aquellas haciendas. Por un lado, ninguna propiedad se orientaba exclusivamente a explotar un molino hidráulico; al contrario, las haciendas diversificaban sus recursos entre distintas actividades productivas: cultivaban tierras de pan llevar (cereales, legumbres), huertos frutales y viñas; criaban ganado mayor y menor. Además, no se limitaban a la producción primaria: invertían en equipamiento e instalaciones para elaborar productos terminados, tanto de origen animal (jabón, sebo, cordobanes, odres de cuero, petacas, zurrones) como de origen vegetal (harina, vinos y aguardientes).

Los datos del padrón de 1738 permitieron conocer -al menos parcialmente- la densidad productiva de algunas haciendas del árido corregimiento de Coquimbo. Poco después aparecieron otros registros correspondientes a molinos no registrados en aquel censo que permitieron completar el panorama general de los avances de la molinería regional 
a mediados del siglo XVIII. En ese sentido, singular valor aportó un registro de 1748 en el cual se entregaban detalles del molino de la hacienda Marquesa la Alta (Cavieres, 1993: 41-42).

El molino de Marquesa la Alta presentaba una línea coherente de continuidad con el proceso regional previo. Se consolidaba una cultura molinera centrada en la fuerza hidráulica, con rueda horizontal y uso de los materiales locales: se usaban las maderas duras de algarrobo para las vigas del edificio y las piezas de mayor desgaste del molino (rodezno y palahierro); en cambio, las maderas blandas (alerce y sauce) se usaban en los ductos para conducir el agua (canales) y los accesorios del molino (tolva y cajón). Al seleccionar y trabajar las maderas, los maestros carpinteros, torneros y ebanistas mostraban el dominio del oficio.

El molino de Marquesa la Alta tuvo también efectos sociales y políticos, equivalentes a la chacra de Quilacán. Su presencia sirvió para consolidar esta localidad como punto de encuentro de arrieros, campesinos, labradores y paisanos que, mientras esperaban la molienda de la harina, establecían y renovaban sus vínculos, intercambiaban noticias y bienes; formaban así un mercado que atrajo a nuevos proveedores de alimentos y provisiones, artesanos y prestadores de servicios, lo cual animó la creación de asentamientos precarios, primero, y cada vez más estables, después. En cierto modo, la inauguración del molino de Marquesa la Alta, en la década de 1740, sentó las bases para la futura fundación de la ciudad deVicuña, noventa años más tarde. Paralelamente, este establecimiento contribuyó a consolidar la red molinera de la cuenda del río Elqui, con referentes en $\mathrm{La}$ Serena, Quilacán (9 kilómetros al este del anterior) y Marquesa la Alta (64 kilómetros al este). Se consolidó así la principal ruta de servicio y transporte del corregimiento de Coquimbo, que permitía enlazar la producción de la costa con el valle de Elqui y los mercados trasandinos. En torno a estos molinos surgían también pulperías y tabernas, las cuales funcionaban como proveedurías para abastecer a las tropas de arrieros durante sus largas travesías.

\section{COLOFÓN: DEL PALACIO REAL A LA INDEPENDENCIA}

La matriz molinera del corregimiento de Coquimbo, iniciada en el siglo XVI y asentada en tiempos de la reconstrucción del Palacio Real de Madrid, maduró en el periodo tardocolonial. Así lo reveló el censo de 1813 cuando se registraron 58 molinos hidráulicos para una población de apenas 29.000 habitantes, con un índice notable de dos molinos cada mil personas. Los sistemas molineros nutrieron y estimularon las actividades agrícolas, mineras, ganaderas y comerciales de todo el corregimiento y contribuyeron a su con- 
solidación como polo socioeconómico relevante dentro de Chile. Como resultado, y a pesar de su aridez, Coquimbo fue reconocido entonces como una de las tres principales provincias de Chile. La Junta de Gobierno que asumió el poder el 16 de noviembre de 1811 se formó con un triunvirato integrado por representantes de Santiago, Concepción y Coquimbo. Con este mismo criterio, el Reglamento Constitucional Provisional estableció que el Senado tendría siete miembros: dos de Coquimbo, dos de Concepción y tres de Santiago (Barros, 1887,VIII: 471, 595). La modesta provincia de Coquimbo surgía como uno de los tres pilares políticos de la naciente república.

Tras la reconquista española del Reino de Chile en la batalla de Rancagua (octubre de 1814) y la migración de los revolucionarios a Mendoza, los nuevos planes para promover la independencia de este país tuvieron a Coquimbo en el centro de la atención. El 8 de mayo de 1815, el patriota chileno exiliado en Argentina, José Miguel Carrera, se dirigió al director supremo del Gobierno rioplatense, Ignacio Álvarez Thomas, para proponer un plan de expedición libertadora a Chile, para expulsar a los realistas y declarar la independencia: "Puede verificarse por Coquimbo cuyos montes se franquean por ciertos puntos en todos los tiempos [...] Nosotros tenemos siempre la retirada expedita por la proximidad de Coquimbo a la cordillera y en caso de imposibilidad para continuar la empresa, traspasaremos la cordillera con toda la inmensa riqueza» (Espejo, 1916:302303). La propuesta carrerina estaba fuertemente impregnada de la imagen del servicio regular de transporte terrestre de carga trasandino asegurado por los arrieros de Coquimbo. El plan circuló en la clase dirigente argentina y nutrió los diseños estratégicos de los dos años posteriores. Se realizaron varias modificaciones y nuevos diseños hasta que, finalmente, la expedición libertadora se puso en marcha en el verano de 1817 por seis rutas distintas. En este proceso, emergió nuevamente Barraza, el cruce de caminos del valle de Limarí, fecundado por sus molinos harineros. Una de las columnas del Ejército de los Andes llegó al lugar y se dispuso a tomar el control de Barraza, el cruce de caminos estratégico del corregimiento de Coquimbo. Los combates de sus inmediaciones (11 de febrero de 1817) marcaron el principio del fin del periodo colonial y el comienzo de la historia independiente de Chile. Paradójicamente, las redes de molinos harineros que sirvieron para consolidar el dominio español en la región en los siglos XVI, XVII y XVIII, se convirtieron en vectores funcionales a las campañas libertadoras y la independencia del Cono Sur de América a comienzos del siglo XIX.

\section{CONCLUSIÓN}

Los molinos hidráulicos harineros marcaron la historia económica y social del corregimiento de Coquimbo durante el periodo colonial. A pesar de la aridez del territorio, la 
disponibilidad de las redes de molinos sirvió para facilitar y estimular la producción agrícola, ganadera y minera, juntamente con las manufacturas derivadas de los productos primarios, particularmente cobres labrados, talabartería, vinos y destilados. Asimismo, estas actividades ser vieron estimuladas y facilitadas por las redes de comercio y transporte tanto terrestre como marítimo. La certeza del abastecimiento del alimento cotidiano afirmó el papel de Coquimbo como portal de ingreso desde el Perú hacia el Cono Sur de América, y sus redes de transporte marítimo y terrestre.

Los molinos se organizaron en tres sistemas molineros situados en La Serena, el valle de Elqui y el valle de Limarí. Estos sistemas funcionaban con actores, estructuras y procedimientos. La estructura comprendía las cadenas de abastecimiento de materia prima (trigo), prestación de servicio (molienda) y distribución en los mercados fundamentalmente internos para asegurar el abastecimiento de la ciudad y los emprendimientos mineros, agrícolas y ganaderos, juntamente con el transporte terrestre y marítimo. Con respecto a los actores, se distinguían los directos y los indirectos. Los actores directos eran los grupos señoriales que construían y hacían funcionar los molinos como plataforma de prestigio social, y los artesanos especializados, sobre todo indígenas y afrochilenos, que desplegaban sus habilidades técnicas para asegurar su funcionamiento. A ello se sumaban dos grupos de actores indirectos: los proveedores de trigo (labradores y hacendados) y los clientes de harina (panaderos, arrieros, pulperos, mineros, comerciantes). Los procedimientos que articulaban a los actores dentro de la estructura eran regulados por el Cabildo y sus respectivas ordenanzas. La alta demanda de trigo del mercado peruano podía reducir los stocks disponibles para los molinos locales, sobre todo en años de malas cosechas; pero en estos casos, los dueños de los molinos, que a la vez tenían fuerte presencia en el Cabildo, establecían regulaciones que garantizaran el flujo triguero hacia los molinos, con lo cual, la actividad no se interrumpía ni en ciclos de malas cosechas. Junto con las normas capitulares se establecieron procedimientos apoyados en usos y costumbres, sobre todo en las zonas alejadas de la ciudad, donde los arrieros funcionaban como articuladores del transporte y el comercio.

Los molinos contribuyeron a consolidar la colonización española en la región y el reconocimiento social de sus capas dirigentes, a la vez que integraron en papeles subalternos las habilidades de pueblos originarios y esclavos afrochilenos. También afirmaron las rutas comerciales que facilitaban la remisión de las riquezas coloniales hacia la capital virreinal. En ese sentido, fueron doblemente funcionales a la consolidación del Imperio español en el Cono Sur. Pero al mismo tiempo, estimularon las economías regionales, los encadenamientos productivos y el surgimiento de polos de desarrollo conducidos por los criollos. Finalmente, estos sistemas molineros contribuyeron, directa o indirectamente, al proceso revolucionario que culminó con la independencia. 


\section{AGRADECIMIENTOS}

Los autores desean expresar su agradecimiento a los revisores externos y editores de $\mathrm{His}_{\text {- }}$ toria Agraria por sus aportes para mejorar la versión original del texto. El presente artículo se ha beneficiado del proyecto 031894LG, financiado por la Dirección de Investigación (DICYT-VRIDEI) de la Universidad de Santiago de Chile.

\section{REFERENCIAS}

Amunátegui, D. (1928). El cabildo de La Serena (1678-1800). Santiago: Imprenta Universo.

Arre, M. (2017). Mulatillos y negritos en el corregimiento de Coquimbo: Circulación y utilización de niños como servidumbre y mano de obra esclava en Chile (1690-1820). Temuco: Universidad de La Frontera.

ARTís, G. (1986). Regatones y maquileros: El mercado de trigo en la ciudad de México (siglo XVIII). México, DF: Centro de Investigaciones y Estudios Superiores en Antropología Social.

BARRIO, J. (2009). La producción, el consumo y la especulación de los cereales en una ciudad de frontera: Orihuela, siglos XIII-Xv. En B. ARÍZAGA \& J. SolórZANo (Eds.), Alimentar la ciudad en la Edad Media (pp. 59-86). Logroño: Instituto de Estudios Riojanos.

BARros, D. (1887). Historia General de Chile. Tomo VIII. Santiago: Rafael Jover.

Bloch, M. (1935). Avènement et conquêtes du moulin à eau. Annales d'histoire économique et sociale, (36), 538-563.

CAVIERES, E. (1993). La Serena en el siglo XVIII: Las dimensiones del poder local en una sociedad regional. Valparaíso: Universidad de Valparaíso.

CERDA, P. (2015). Cultura Elqui: Pueblo originario delValle de Coquimbo, Chile. Santiago: Pehuén.

COFRÉ, C. \& STEWART, D. (2020). Viña, alambiques y "veinticinco botijas de pisco»: Alhué, 1717. RIVAR, 7 (20), 88-107. https://scielo.conicyt.cl/scielo.php?script=sci_arttext\&pid=S0719-49942020000200088\&lng=es\&nrm=iso\&tlng=es

Concha, M. (1871). Crónica de La Serena: Desde su fundación hasta nuestros días 15491870. Santiago: Imprenta La Reforma.

Córdoba, R. (2002). Sobre el origen de los molinos de regolfo. En Actas de III fornadas Internacionales de Molinología (pp. 197-204). Murcia: Consejeria de Educacion y Cultura. 
CóRdoba, R. (2003). Los molinos hidráulicos de la cuenca del Guadalquivir a fines de la Edad Media: Instrumental y equipamiento técnico. Anuario de Estudios Medievales, 33 (1), 291-337.

CoRTÉs, H. (2003). Evolución de la propiedad agraria en el Norte Chico (siglos XVI-XIX). En P. Livenais \& X. ARANDA (Eds.), Dinámicas de los sistemas agrarios en Chile árido: La región de Coquimbo (pp. 33-64). Marseille: IRD.

Cortés, H. (2018). El Cabildo de La Serena y la administración de justicia en el Corregimiento de Coquimbo: 1690-1808. La Serena: Colecciones Digitales, Subdirección de Investigación, Servicio Nacional del Patrimonio Cultural.

DíAZ, I. (2010). La evolución de la alimentación y la gastronomía en España. En F. ADRIÀ, I. Moyano \& M. Simón (Eds.), La cocina en su tinta (pp. 121-154). Madrid: Biblioteca Nacional.

Eizykovicz, J. (2013). Breve historia del pan de Buenos Aires. Buenos Aires: La Era.

Espejo, G. (1916). El Paso de los Andes: Crónica histórica de las operaciones del Ejército de los Andes para la restauración de Chile en 1817. Buenos Aires: Librería La Facultad. EspinosA, R. (2012). El molino de Tuzcacuaco: Antecedentes de la hacienda Molino de Flores, Texcoco, Estado de México, 1567-1667. Boletín de Monumentos Históricos, (25), 94-108. https://mediateca.inah.gob.mx/repositorio/islandora/object/articulo:9669

FigueroA, P. (2006). Los molinos hidráulicos en Mendoza (Argentina) durante el periodo colonial (S. XVI, XVII, XVIII). Universum, 21 (1), 28-47. http://dx.doi.org/10.4067/ S0718-23762006000100003

GARCÍA, A. \& DAMIANI, O. (2020). Sistemas de riego y agricultura prehispánica en el centro oeste de Argentina. RIVAR, 7 (20), 22-45. https://scielo.conicyt.cl/scielo.php? script=sci_arttext\&pid=S0719-49942020000200022\&lng=es\&nrm=iso\&tlng=es

Gómez GERARDo, V. (2007). Los molinos hidráulicos del valle de México: Innovaciones tecnológicas en el siglo XIX. I Congreso Latinoamericano de Historia Económica. Montevideo, 5-7 de diciembre.

Gómez Gerardo, V. (2016). La tecnología de molienda de trigo en la ciudad de México (siglos XVI-XIX). International Conference Old and New Worlds: The Global Challenges of Rural History. Lisboa, 27-30 de enero.

InIESTA, M. L., OTs, M. J. \& MANCHADO, M. (2020). Prácticas y tradiciones alimenticias prehispánicas y de la colonia temprana en Mendoza (centro oeste de Argentina): Un aporte desde la arqueología y la etnohistoria. RIVAR, 7 (20), 46-66.

KIRCHNER, H. (2011). Watermills in the Balearic Islands During the Muslim Period. En J. Klápste \& P. Sommer (Eds.), Processing, Storage, Distribution of Food: Food in the Medieval Rural Environment (pp. 45-55). Turnhout: Brepols. (Ruralia, 8).

Lacoste, P. (Coord.) (2016). El pisco nació en Chile. Santiago: RIL.

Lacoste, P. (2018). Molinos harineros en Chile (1569-1841). América Latina en la Historia Económica, 25 (3), 103-132. http://dx.doi.org/10.18232/alhe.907 
Lacoste, P., Castro, A., Soto, N., Polanco, C., Rendón, B., Jiménez, D., Muñoz, J. G., Cruz, E., Mujica, F., Adunka, M. \& Martínez, F. (2016). Cobre labrado, alambique y aguardiente: Chile y Argentina, 1586-1850. Quinto Sol, 20 (1), 1-29. http://www.scielo.org.ar/scielo.php?script=sci_arttext\&pid=S1851-28792016 $000100001 \& \operatorname{lng}=\mathrm{es} \& \mathrm{nrm}=\mathrm{iso} \& \mathrm{t} \operatorname{lng}=\mathrm{es}$

Lacoste, P., Lacoste, M. \& Mujica, F. (2019). Jabón de Mendoza: Aporte para el estudio del comercio trasandino (1697-1870). Iberoamericana (Alemania), (70).

Lacoste, P., Pszczólkowski, P., NúÑEZ, E., CofrÉ, C. \& Lacoste, M. (2020). El arriero trasandino como intermediador etnobotánico en la propagación de variedades de vid entre Chile y Argentina. En Huellas inéditas del VI Congreso Internacional de Etnobotánica (pp. 185-195). Córdoba: Universidad de Córdoba.

López, R. (2002). El Molino de Santa Mónica: Historia de una empresa colonial. México, DF: El Colegio Mexiquense.

Martínez Compagnon, B. (1785). Trujillo del Perú. Tomo II. Madrid: CSIC. http://www.cervantesvirtual.com/obra-visor/trujillo-del-peru--volumen-ii/html/

Morales, H. (2008). Los molinos de La Asunción y San Miguel en Tecamachalco y Acatzingo, Estado de Puebla (resultados de la arqueología industrial). Apuntes, 21 (1), 136145. http://www.scielo.org.co/pdf/apun/v21n1/v21n1a09.pdf

Morales, H. (2010). Haciendas, molinos y camino a la fábrica en los orígenes de la industria mexicana (Historia económica y arqueología industrial). Boletín de Monumentos Históricos, (18), 96-112.

Morales, L. M. (2006). Trigo, trojes, molinos y pan, el dorado de la oligarquía poblana. Theomai, (13), 1-13. http://revista-theomai.unq.edu.ar/NUMERO13/artmorales $\% 201 . h t m$

Moreno, A. \& López Gálvez, M.Y. (2012). Los molinos como impulsores de la industria medieval: Ingenios para la obtención de alimentos. En Actas delVIII Congreso Internacional de Molinología. Tui, 28-30 de abril.

Naranjo, C. (2017). Historia mínima de las Antillas: Las Antillas hispanas y las Antillas británicas: Dos modelos coloniales en las islas del Caribe. Madrid:Turner/El Colegio de México.

ORTEGA, M. (2018). El Toboso, prólogo del escenario de la aventura de los molinos: ¡Realidad o ficción! En Actas del XI Congreso Internacional de Molinología (pp. 59-64). Palma: Consell Insular de Mallorca.

Ovalle, A. DE (1646). Histórica relación del Reyno de Chile. Roma: Francisco Ceballos. Pedregosa, R. \& Jiménez Comino, F. (2012). Los molinos hidráulicos harineros de la Ribera de Mairena Montefrío (Granada): Datos históricos para su conocimiento: La arquitectura del molino de Peinado o Fortiz. En Actas del VIII Congreso Internacional de Molinología. Tui, 28-30 de abril.

Pereira, E. (2013). Apuntes para la historia de la cocina chilena. Santiago: Eqbar. 
Pinto, J. (1980). Población del Norte Chico en el siglo XVIII: Crecimiento y distribución de una región minero agrícola de Chile. La Serena: Talleres Gráficos Universidad del Norte.

Pizarro, G. (2014). Las comunidades agrícolas de la Región de Coquimbo: Origen y desarrollo de un sistema agro-ganadero del Norte Chico. Santiago: Gobierno Regional de Coquimbo.

Premat, E. (2015). Tres haciendas jesuíticas en el Reino de Chile (siglo XviII): Calera de Tango, El Buen Viaje y Puyuta. RIVAR, 2 (4), 57-70. http://www.revistarivar.cl/ images/html/rivar4/art4.html

RAmíreZ, C. (1984). El molino harinero artesanal de Chiloé. Cuadernos de Estudios Gallegos, 5 (125), 143-156.

Romero, C. (2009). Los molinos de sangre animal y esclava, en los ingenios azucareros de Cuba: Recreación histórica en los siglos xvIII y XIx. En Actas delV Congreso Internacional de Molinologia, (pp. 149-152). Alcázar de San Juan: Junta de Comunidades de Castilla La Mancha.

RAMÓN, A. DE \& LARRAín, J. M. (1981). Orígenes de la vida económica chilena (16591808). Santiago: Centro de Estudios Públicos.

Sahady, A., Bravo, J. \& Quilodrán, C. (2016). Patrimonio en peligro de extinción: Los molinos de agua en Chiloé. AUS, (20), 28-33. https://doi.org/10.4206/aus.2016.n2005

SatizÁbal, A. E. (2004). Molinos de trigo en la Nueva Granada (siglos XVII-XVIII): Arquitectura industrial, patrimonio cultural inmueble. Bogotá: Universidad Nacional de Colombia.

SatizÁbal, J. (2018). Molinos de trigo en la Nueva Granada, siglos XVII-XVIII. En Actas del XI Congreso Internacional de Molinología (pp. 231-245). Palma: Consell Insular de Mallorca.

VIvar, J. (2001 [1558]). Crónica de los reinos de Chile. Madrid: Dastin.

Valdivia, P. (1929 [1545]). Cartas de Pedro de Valdivia que tratan del descubrimiento y conquista de Chile. Sevilla: Establecimiento Carmona Velázquez. (Edición de José Toribio Medina). 